\title{
Evaluation of the Compliance of Orthodontists to Infection Control Procedures in South India: A Questionnaire Based Study
}

\author{
Sharath Kumar Shetty ${ }^{1}$, Mahesh Kumar Y², Lekshmi G Vijayan ${ }^{3 *}$, Vijayananda K Madhur ${ }^{4}$
}

\author{
${ }^{1}$ Professor \& HOD, Department of Orthodontics and Dentofacial Orthopaedics, K. V. G. Dental College and Hospital, Sullia, Karnataka, India \\ ${ }^{2}$ Professor, Department of Orthodontics and Dentofacial Orthopaedics, K. V. G. Dental College and Hospital, Sullia, Karnataka, India \\ ${ }^{3}$ Post Graduate Student, Department of Orthodontics and Dentofacial Orthopaedics, K. V. G. Dental College and Hospital, Sullia, Karnataka, India \\ ${ }^{4}$ Reader, Department of Orthodontics and Dentofacial Orthopaedics, K. V. G. Dental College and Hospital, Sullia, Karnataka, India
}

DOI: $10.36347 /$ sjds.2020.v07i12.010

| Received: 09.12.2020 | Accepted: 23.12.2020 | Published: 30.12.2020

*Corresponding author: Lekshmi G Vijayan

Abstract

Original Research Article

COVID-19 emerged as a global pandemic in early 2020, affecting more than 200 countries and territories. The infection is highly contagious, with disease transmission reported from asymptomatic carriers, including children. So in todays orthodontic practice, disease control must undergo major reevaluation and restructuring and must be given prime importance. The aim of this study was to evaluate by means of questionnaire, sterilization and dis $\neg$ infection methods employed in the practice of orthodontics in South India and the compliance of orthodontists to these methods. The questionnaire study was conducted using an online survey from July 2020 to December 2020.

Keywords: Infection control, COVID19, Orthodontic clinic.

Copyright $\odot 2020$ The Author(s): This is an open-access article distributed under the terms of the Creative Commons Attribution 4.0 International License (CC BY-NC 4.0) which permits unrestricted use, distribution, and reproduction in any medium for non-commercial use provided the original author and source are credited.

\section{INTRODUCTION}

Infection control is crucial for orthodontists and for patient health. The concept of sterilization and disinfection was introduced into the dental practice with the recognition of hepatitis B as an occupational disease in 1975, and considerable steps have been taken in infection control procedures with increasing prevalence of human immunodeficiency virus (HIV)/acquired immune deficiency syndrome (AIDS) in the mid-1980s [1].

COVID-19 emerged as a global pandemic in early 2020, affecting more than 200 countries and territories. The infection is highly contagious, with disease transmission reported from asymptomatic carriers, including children. It spreads through personto-person contact via aerosol and droplets. The practice of social distancing - maintaining a distance of 1-2 m or $6 \mathrm{ft}$ - between people has been recommended widely to slow or halt the spread. In orthodontics, this distance is difficult to maintain, which places orthodontists at a high risk of acquiring and transmitting the infection [2].

Orthodontists usually do not perform comprehensive surgical procedures, but they are obliged to use appropriate sterilization techniques to prevent cross-infection in daily practice. This is also important from an ethical and legal point of view [3, 4]. However, the studies have found that orthodontists have lower compliance to the infection control procedures than dentists. The main reason for this is that they work on pediatric cases, they do not perform procedures in deep tissues, sterilization procedures result in the loss of time and money, and sterilization procedures cause corrosion in orthodontic pliers $[5,6]$.

In the present study, we aimed to evaluate by means of questionnaire, sterilization and disinfection methods employed in the practice of orthodontics in South India and the compliance of orthodontists to these methods.

\section{MATERIALS AND METHODS}

The present study was a cross- sectional questionnaire-based survey conducted among the orthodontists in South India between July 2020 and December 2020. A 23-item questionnaire were included in the study to evaluate the compliance of orthodontists to infection control procedures. The questionnaire was in English language and open ended and selfadministered. The Ethical approval was obtained from the Ethics committee KVG dental college Sullia, Dakshina Kannada. Soft copy of questionnaire was delivered through whatsapp and whatsapp groups to maximum possible number of orthodontists in South India including PG residents. A total of 205 responses were included in the study. 
Questionnaire

1. How long have you been working as a dental practitioner/orthodontist?

a. $0-5$

b. $6-10$

c. $11-15$

d. $16-20$

e. More than 20 years

2. Place of work?

a. Private Clinic

b. Government Hospital

c. Public Health Care Center

3. Daily patient volume?

a. $0-5$

b. $6-10$

c. $11-15$

d. $16-20$

e. 20

4. Number of dental assistant?
a. 0
b. 1
c. 2
d. 3
e. 4
f. 5
g. 5

5. Is there a written infection control program at your clinic?

a. Yes

b. No

6. Is there a separate sterilization room?

a. Yes

b. No

7. How do you sterilize dental handpieces?

a. Dry-heat sterilizer

b. Autoclave

c Cassette autoclave

d. Cold sterilization

8. How do you sterilize hand instruments/orthodontic pliers?

a.Autoclave

b.In a dedicated device (dental handpiece autoclave)

c.Cold sterilization

9. How do you sterilize your cheek retractor?
a. Autoclave
b. Cold sterilization

10. Do you sterilize molar bands after purchase?

a. Yes

b. No
11. How do you sterilize molar bands after trial in the patient?
a. Dry-heat sterilizer
b. Autoclave
c. Cold sterilization

12. Do you sterilize mini implants after purchase?
a. Yes
b. No

13. Do you use recycled brackets/orthodontic materials?
a. Yes
b. No

14. Do you disinfect impressions or appliances to be delivered to an outer laboratory?
a. Yes
b. No

15. How do you disinfect the impression?
a. Using a disinfectant solution
b. UV irradiation

16. Which type of gloves do you use during cleaning of instruments and environmental cleaning?
a. Examination gloves
b. Kitchen-type gloves
c. I do not wear

17. How do you perform surface cleaning?

a. Disinfect with alcohol

b. Disinfect with hypochlorite solution

c. Other disinfectants

d. Dont do at all

18. How do you disinfect your dental chair?

a. Cover the handles with a disposable foil

b. Using a disinfectant solution

19. Do you use a separate protective mask for each patient?

a. Yes

b. No

20. Have you had hepatitis B vaccine?

a. Yes

b. No

21. Do you advice the patient to use an antimicrobial mouthwash before procedure?

a. Yes

b. No

22. What are the necessary precautions you are taking during Covid 19 pandemic?

a. Surgical mask

b. Respirators(N 95)

c. Using PPE

d. All the above 
23. How do you purify the air inside the clinic?

a.Exhaust fan and ventilation

b. Hepa purifiers

c. Fumigation

d. UV irradiation

\section{RESULTS}

The responses of a total of 205 orthodontists were included in the study. Of the total respondents, $99.5 \%$ have an experience less than 20 years. $85.3 \%$ work in private offices and $12.7 \%$ work in Government hospitals. In terms of daily patient capacity, $74.5 \%$ of the respondents have over 6 patients. The results of the study are presented with the help of pie charts below.

\section{N-Number of Response}

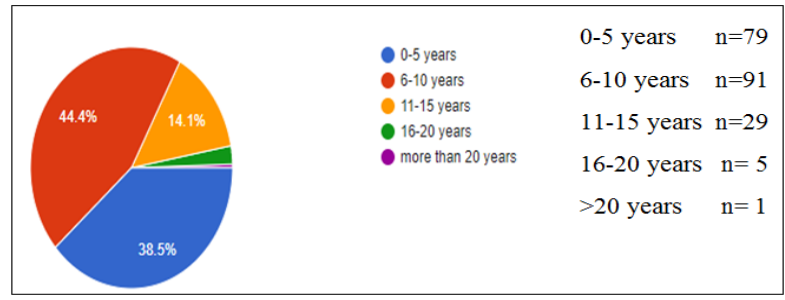

Fig-1: Experience in practice

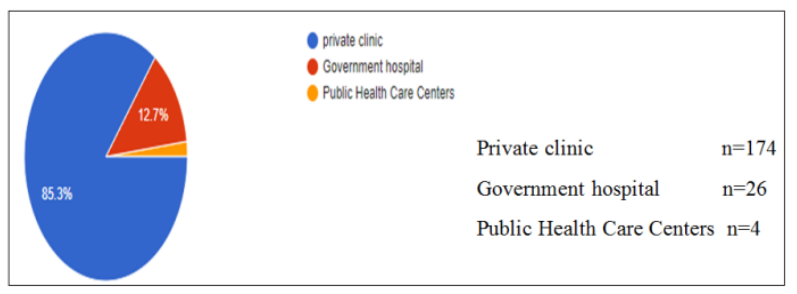

Fig-2: Place of work

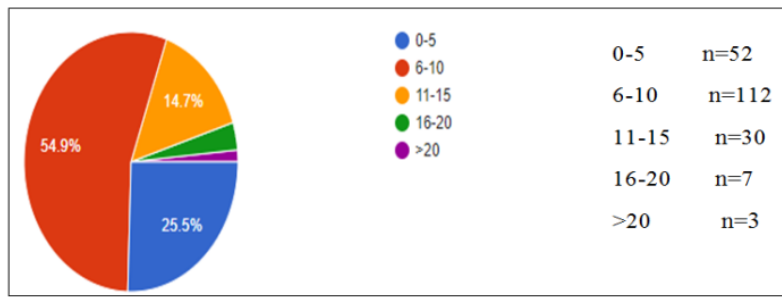

Fig-3: Daily patient capacity

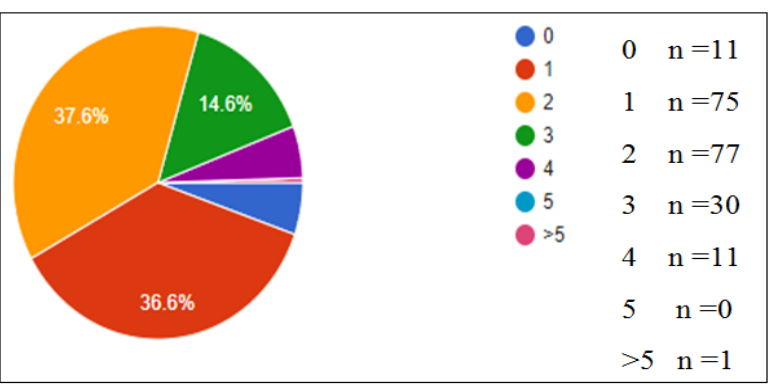

Fig-4: Number of dental assistant

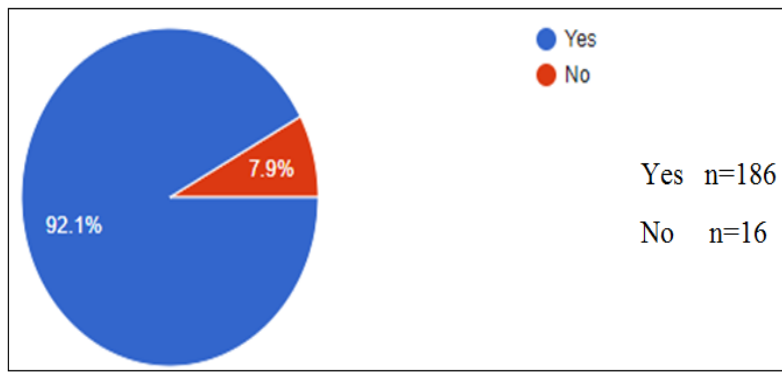

Fig-5: Written infection control program at clinic

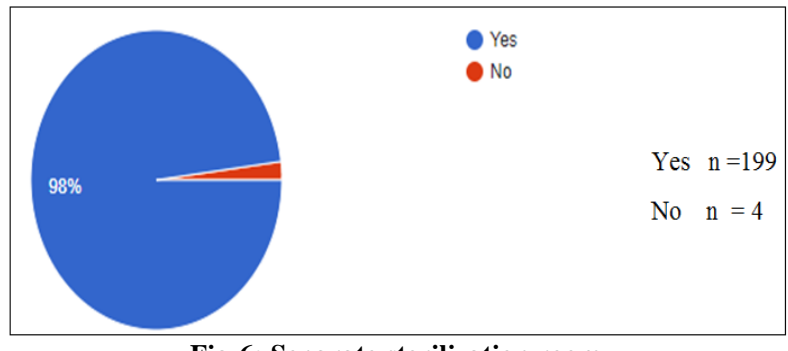

Fig-6: Separate sterilization room

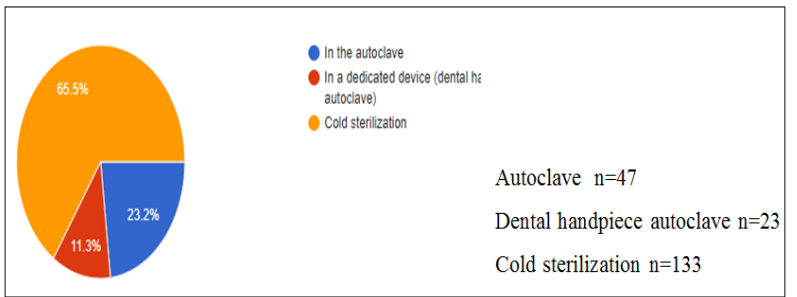

Fig-7: Sterilization of dental handpieces

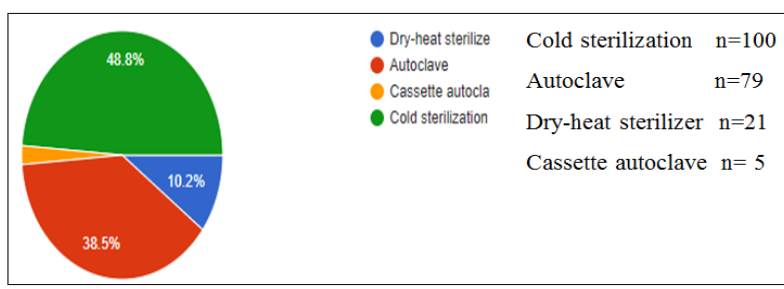

Fig-8: Sterilization of hand instruments/orthodontic pliers

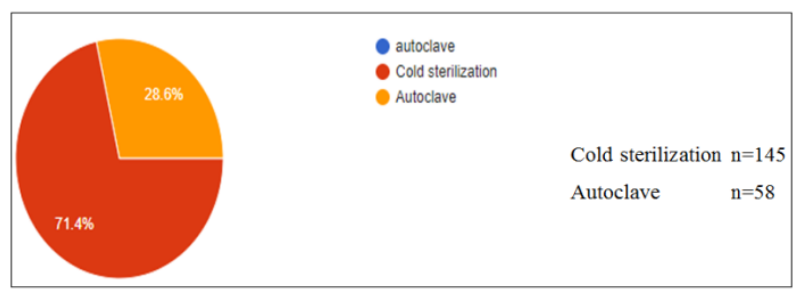

Fig-9: Sterilization of cheek retractor

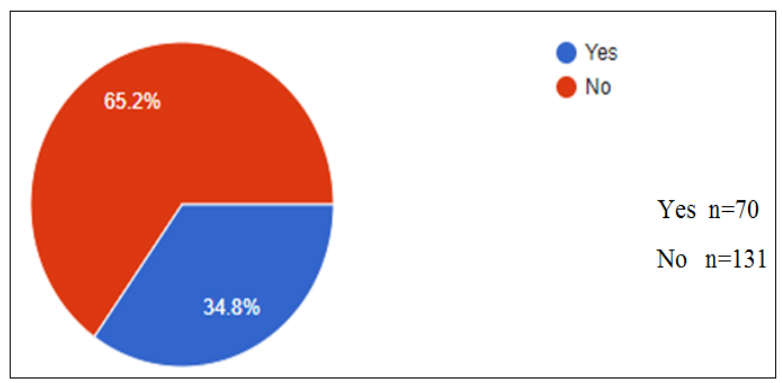

Fig-10: Sterilization of molar bands after purchase 


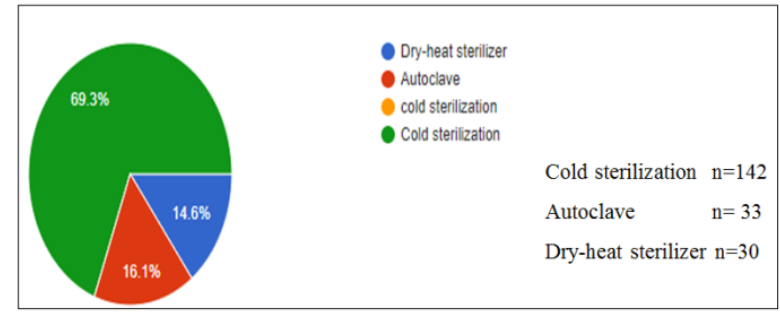

Fig-11: Sterilization of molar bands after trial in the patient

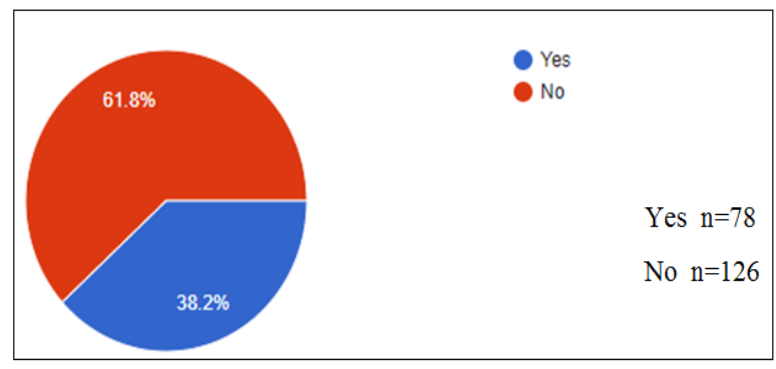

Fig-12: Sterilization of mini implants after purchase

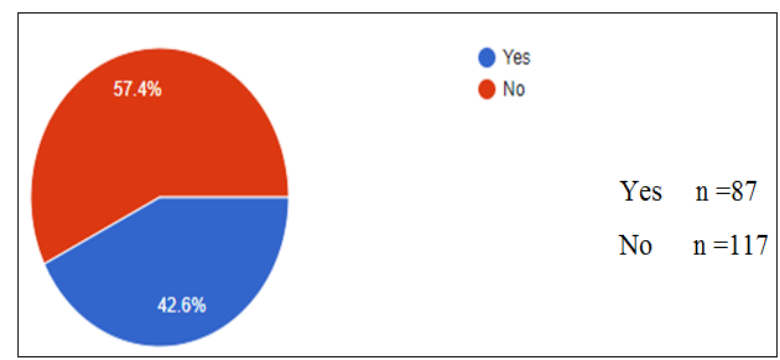

Fig-13: Recycling of orthodontic materials/brackets

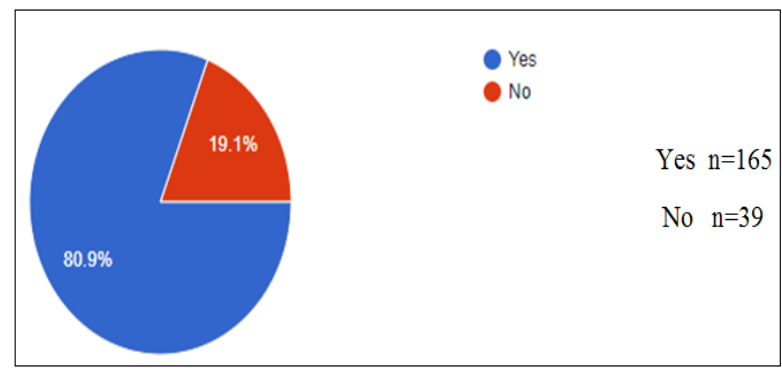

Fig-14: Disinfection of impressions or appliances to be delivered to an outer laboratory

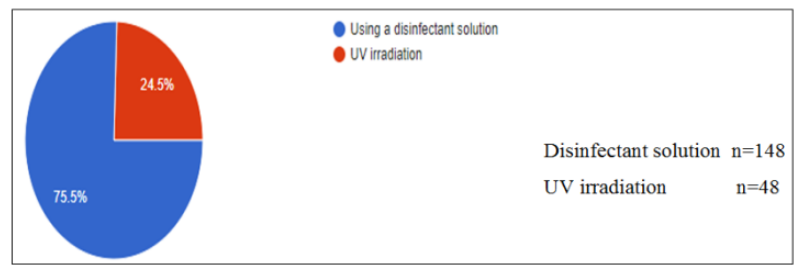

Fig-15: Methods of disinfection of the impression

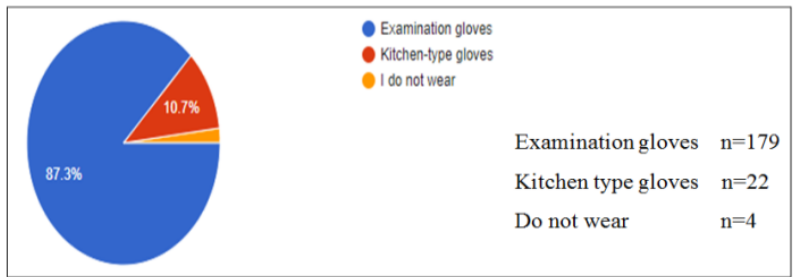

Fig-16: Gloves used during cleaning of instruments and environmental cleaning

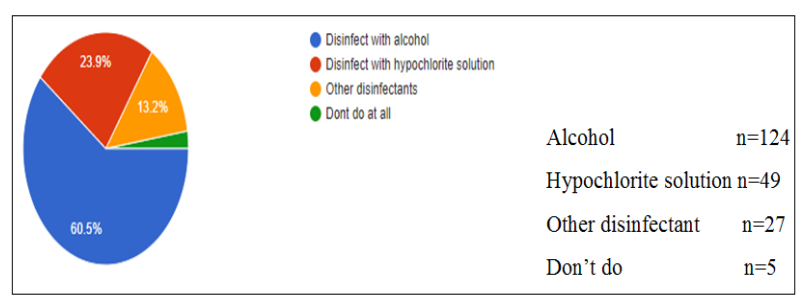

Fig-17: Surface cleaning

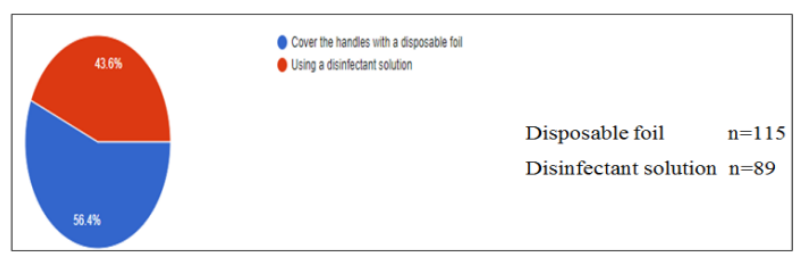

Fig-18: Disinfection of dental chair

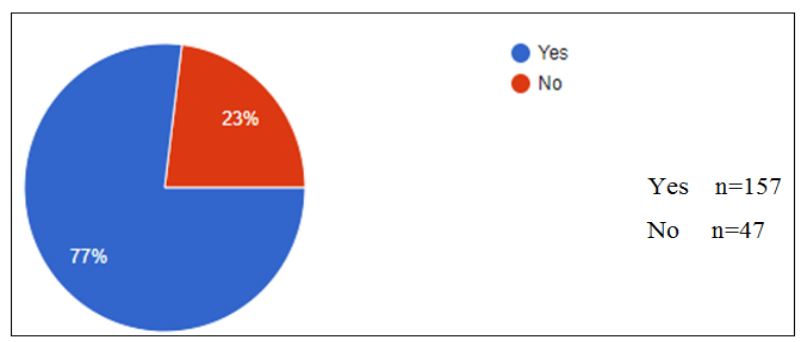

Fig-19: Separate protective mask for each patient

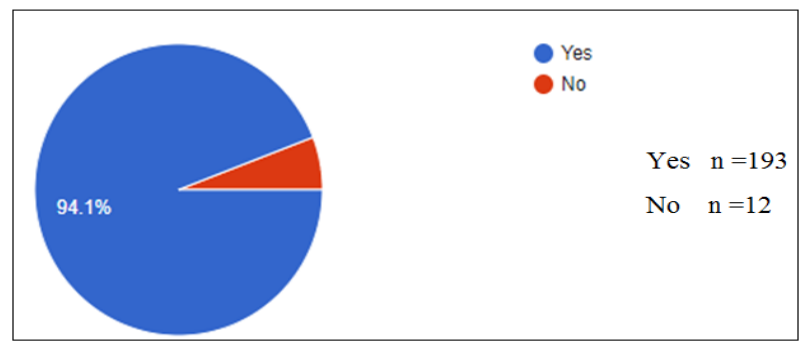

Fig-20: Hepatitis B vaccination

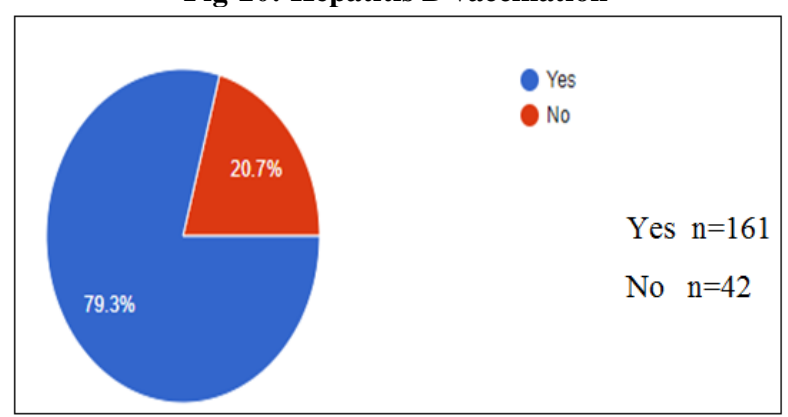

Fig-21: Advicing patients to use antimicrobial mouthwash before procedure 


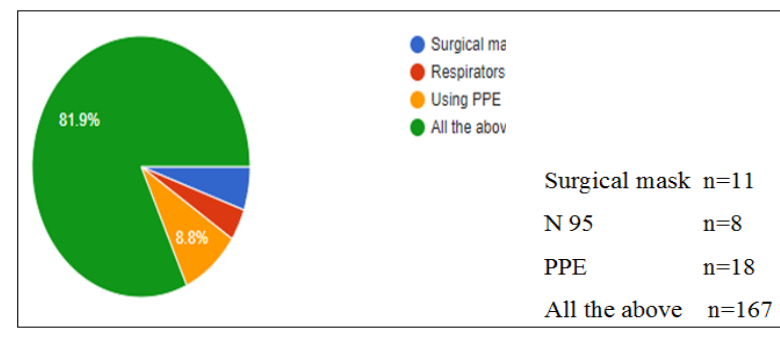

Fig-22: Necessary precautions taking during Covid 19 pandemic

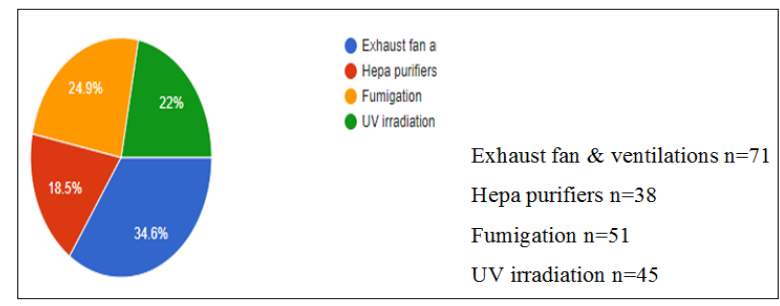

Fig-23: Air disinfection in dental clinic

$98 \%$ of respondents had separate sterilization room and $92.1 \%$ had written infection control program at their clinic. Rate of using cold sterilization for orthodontic pliers and hand instruments was $48.8 \%$, the rate of using autoclave was $38.5 \%$, and the rate of using dry-heat sterilizer was $10.2 \%$. For dental hand piece $65.5 \%$ were using cold sterilization.Majority were not following presterilization of mini implants $(61.8 \%)$ and bands $(65.2 \%)$. Whereas the rate of sitting molar bands in disinfectant solution after trial in the patient was $69.3 \%$, the rate of autoclave sterilization was $16.1 \%$. The rate of using examination gloves was $87.3 \%$ kitchen-type gloves during cleaning of instruments and environmental cleaning was $10.7 \%$.

Hepatitis B immunization rate was $94.1 \%$. Majority were advicing antimicrobial mouthwash before procedure $(79.3 \%)$ and were following all the necessary precautions during COVID 19 including PPE and $\mathrm{N} 95$ masks (81.9\%).

\section{DISCUSSION}

Eventhough Orthodontist does not perform oral surgery, effective infection control must be a routine component of professional activity. The results of this study showed that majority of respodents had separate sterilization room (98\%) and written infection control program $(92.1 \%)$ at their clinic which is inevitable for very clinic. Work load increases with daily patient volume, and accordingly, number of dental assistant increases. In the practice of experienced orthodontists, number of dental assistant was found to be higher with increasing daily patient volume.

The rate of wiping off the outer surface of dental handpieces (cold sterilization) was $66.8 \%$, and the rate of using autoclave sterilization was $23.2 \%$, whereas the rate of using dental handpiece autoclave was $11.3 \%$. Although wiping dental handpieces with disinfectant solutions without performing sterilization is an inappropriate and an inefficient means of sterilization, the rate of this method was considerably high. According to the study by Vendrell et al., [7] published in 2002, disinfection with ethanol, propanol (Incidur®) spray, and isopropanol (Iso-Septol) spray was not satisfactory in reducing the number of microorganisms. Dental handpieces must be therefore sterilized using the autoclave, and wiping the outer surface with a disinfectant solution must be abandoned [7].

If cross-infection prevention is to be taken seriously in orthodontics, then probably all instruments should be routinely sterilized using an autoclave. Some studies have showed that routine autoclaving of orthodontic pliers using a centralized system does not causes any more damage than chair side cold disinfection [8]. As an ideal sterilization method, the rate of using autoclave does not exceed $50 \%$. This finding suggests an inadequacy in sterilization of orthodontic pliers and hand instruments.

Although auto- claving is the safest way to remove infectious micro- organisms from contaminated instruments including cheek retractor, not all available cheek retractors are autoclavable one. Authors recommended cheek retractors be cleaned using a highlevel cold disinfectant. Both alcohol- and chlorinebased disinfectants come in many different forms, and they must be used according to the manufacturers' instructions [9]. The rate of cold disinfection for cheek retractor was $71.4 \%$.

The rate of sterilization for the purchased molar bands before trial in the patient was $34.8 \%$, the rate of sitting in a disinfectant solution after trial was $69.3 \%$, and the rate of autoclave sterilization was $16.1 \%$. Although the rate of sterilization for the purchased molar bands was low, the rate of sterilization after trial in the patient was found to be higher and majority followed cold sterilization.The rate of sterilization of mini implants before usage and after purchase was only $38.2 \%$.

The rate of using recycled brackets/orthodontic materials was found to be $42.6 \%$. In a study published by Oshagh et al., in 2012, softening of archwires was reported after sterilization in the autoclave; however, this change was reported to be at low levels and does not pose a problem in clinical practice [10].

Dental impression materials can act as vectors transmitting a significant amount of microorganisms. Sodium hypochlorite disinfection is an efficient disinfection method for alginate impressions. Tap water rinsing reduces microbial load but does not eliminate the cross-infection potential of alginate [28]. The British Dental Association in the Health Technical Memorandum 01-05 recommends disinfection and decontamination of dental impressions before dispatching them to the dental laboratories, and states 
that the responsibility for ensuring dental impressions are both disinfected and labelled as such before being sent to dental laboratory lies solely with the dentist who should inform the dental lab technicians about the status of impression disinfection $[11,12]$. The rate of the disinfection of impression before delivering to laboratory was $80.9 \%$ and of that $75.5 \%$ followed disinfection using a disinfectant solution and $24.5 \%$ followed UV irradiation.

The rate of using examination gloves instead of thick kitchen-type gloves during cleaning of instruments and environmental cleaning was $87.3 \%$.

Surfaces that cannot be sterilized must be disinfected effectively. These surfaces include the airwater sprayers, aspirator heads, reflector arms, cuspidors, drawers, head rest and arms.

Suitable clinic and instrument setting will reduce the surfaces to be disinfected. If the chair's positions can be controlled using a pedal and cuspidors controlled by buttons at the level of the elbow or the knee, hand contact is therefore minimized [13]. Sodium hypochlorite $1 \%$ or solutions including $70 \%$ alcohol are used for surface disinfection in orthodontic clinics. Iodine solutions used for disinfection are cheap, easily stored and highly effective. The only disadvantage is the staining characteristic of iodine. There are types that can be diluted in water or in $70 \%$ isopropyl alcohol [13]. The rate of disinfection with alcohol was $60.5 \%$, with hypochlorite was $23.9 \%$ and $13.2 \%$ was using other disinfectants. For disinfection of dental chair, $56.4 \%$ of respondents used the method of covering handles with disposable foils and $43.6 \%$ used the method of wiping with disinfectant solution.

$77 \%$ were using separate mask for each patient and $94.1 \%$ had hepatitis B immunization. $79.3 \%$ were advicing patient to take a antimicrobial mouth wash before procedure.

Orthodontist should wear a lab coat, face mask and hand gloves as a general precautionary measure. Disposable gowns, surgical masks, protective eyeglasses and plastic face masks should be worn during procedures that are likely to splash blood, saliva and oral fluids [5]. As a result of the pandemic, the routine use of complete personal protective equipment may be advisable. Eventhough this equipment, that's usefulness is unquestionable, is very uncomfortable in the day-to-day clinical activity and also hinders psychological interaction with the patient [2]. The rate of using PPE kit and N95 mask during procedure during the time of study was $81.9 \%$.

Various devices/ methods, including ventilation system, ultraviolet lamps, high-volume evacuator, automated room disinfection systems with hydrogen peroxide vapor (fumigation) are used for room surfaces and air disinfection [14-16]. The rate of using exhaust fans and ventilation for air disinfection was $34.6 \%$. $18.5 \%$ used HEPA purifiers, $24.9 \%$ used fumigation method and $22 \%$ used UV irradiation.

\section{CONCLUSION}

1. The rate of using autoclave for sterilizing hand piece was $11.3 \%$ and for orthodontic pliers and hand instrumnts, it did not exceed $50 \%$. This finding suggests an inadequacy in sterilization.

2. Although the rate of sterilization for the purchased molar bands was low, the rate of sterilization after trial in the patient was found to be higher and majority followed cold sterilization.

3. The rate of sterilization of mini implants before usage and after purchase was only $38.2 \%$.

4. The rate of using examination gloves instead of thick kitchen-type gloves during cleaning of instruments and environmental cleaning was $87.3 \%$.

5. Covid 19 disease has altered the entire dental community and in todays orthodontic practice, disease control must undergo major reevaluation and restructuring. The result of the study showed that the compliance of orthodontist to infection control procedure has improved in South India during Covid time, yet need to be still improved.

Effective infection control must be a routine component of professional activity. Thorough understanding of the application of sterilization will help ensure safety from the invisible but deadly world of microbial pathogens. Always "Prevention is better than cure".

\section{REFERENCES}

1. Çelikel AD, Ekmekçioğlu H, Külekçi G, Fıratlı S. Evaluation of the Compliance of Orthodontists to Infection Control Procedures in Turkey. Turkish journal of orthodontics. 2018 Jun;31(2):37.

2. García-Camba P, Marcianes M, Morales MV. Changes in orthodontics during the COVID-19 pandemic that have come to stay. American Journal of Orthodontics and Dentofacial Orthopedics. 2020 Oct 1;158(4):e1-3.

3. Mulick JF. Upgrading sterilization in the orthodontic Office. Am J Orthod. 1986; 89:34651.

4. Payne GS. Sterilization and disinfection in the orthodontic office: A practical approach. Am J Orthod. 1986; 90:250-2.

5. Starnbach H, Biddle P. A pragmathic approach to asepsis in the orthodontic office. Angle Orthod. 1980; 50: 63-6.

6. Holht WF, Miller CH, Neeb JM, Sheldrake MA. Sterilization of orthodontic instruments and bands in cassettes. Am J Orthod. 1998; 98: 411-6.

7. Vendrell RJ, Hayden CL, Taloumis LJ. Effect of steam versus dry-heat sterilization on the wear of orthodontic ligature-cutting pliers. Am J Orthod Dentofacial Orthop. 2002; 121; 467-71. 
8. Jones ML. An initial assessment of the effect on orthodontic pliers of various sterilization/disinfection regimes. British journal of orthodontics. 1989 Nov;16(4):251-8.

9. Thompson C. Health and safety issues pertaining to dental photographic mirrors and cheek and lip retractors. Journal of Audiovisual Media in Medicine. 2002 Jan 1;25(2):54-8.

10. Oshagh M, Hematiyan MR, Mohandes Y, Oshagh MR, Pishbin L. Autoclaving and clinical recycling: Effects on mechanical properties of orthodontic wires. Indian J Dent Res. 2012; 23:638-42.

11. Correia-Sousa J, Tabaio AM, Silva A, Pereira T, Sampaio-Maia B, Vasconcelos M. The effect of water and sodium hypochlorite disinfection on alginate impressions. Revista Portuguesa de Estomatologia, Medicina Dentária e Cirurgia Maxilofacial. 2013 Jan 1;54(1):8-12.

12. Al Mortadi N, Al-Khatib A, Alzoubi KH, Khabour OF. Disinfection of dental impressions: knowledge and practice among dental technicians. Clinical, cosmetic and investigational dentistry. 2019;11:103.

13. Spaulding EH. Chemical disinfection of medical and surgical materials. In: Lawrence C, Block SS, editors. Disinfection, sterilization, and preservation. Philadelphia: Lea and Febiger. 1968:517-531.

14. Otter JA, Donskey C, Yezli S, Douthwaite S, Goldenberg S, Weber DJ. Transmission of SARS and MERS coronaviruses and influenza virus in healthcare settings: the possible role of dry surface contamination. Journal of Hospital Infection. 2016 Mar 1;92(3):235-50.

15. Meng L, Hua F, Bian Z. Coronavirus Disease 2019 (COVID-19): emerging and future challenges for dental and oral medicine. J Dent Res. 2020; 99: 481-487.

16. Harrel SK, Molinari J. Aerosols and splatter in dentistry: a brief review of the literature and infection control implications. J Am Dent Assoc. 2004; 135: 429-437.

17. Schwartz Z, Lohmann CH, Blau G, Blanchard CR, Soskolne AW, Liu Y, Cochran DL, Dean DD, Boyan BD. Re- use of implant coverscrews changes their surface properties but not clinical outcome. Clinical oral implants research. 2000 Jun;11(3):183-94.

18. Sonis AL. Air abrasion of failed bonded metal brackets: a study of shear bond strength and surface characteristics as determined by scanning electron microscopy. American Journal of Orthodontics and Dentofacial Orthopedics. 1996; 110(1):96-98.
19. Pringle RA, Leman RB, Kratz JM, Gillette PC. An argument for pacemaker reuse: pacemaker mortality in 169 patients over ten years. Pacing and Clinical Electrophysiology. 1986; $9(6$ Pt2):1295-1298.

20. Grimandi G, Sellal O, Grimandi F, Crochet D. Risks of reusing coronary angioplasty catheters: results of an experimental study. Catheterization and Cardiovascular Diagnosis. 1996(2); 38:123130

21. Mattos CT, Ruellas AC, Sant'Anna EF. Effect of autoclaving on the fracture torque of miniimplants used for orthodontic anchorage. Journal of orthodontics. 2011 Mar;38(1):15-20.

22. Akyalcin S, McIver HP, English JD, Ontiveros JC, Gallerano RL. Effects of repeated sterilization cycles on primary stability of orthodontic miniscrews. The Angle Orthodontist. 2013 Jul;83(4):674-9.

23. Amitha H, Munshi AK. Effect of Chlorhexidine Gluconate Mouthwash on the Plaque Microflora in Children Using Intraoral Appliances. J Clin Pediatr Dent. 1995; 20:23-9.

24. Lessa FCR, Enoki C, YokoIto I, Faria G, Matsumoto MAN, Filho PN. In-vivo Evaluation of the Bacterial Contamination and Disinfection of Acrylic Baseplates of Removable Orthodontic Appliances. Am J Orthod Dentofacial Orthop. 2007; 131:705.e11-705.e17.

25. Correia-Sousa J, Tabaio AM, Silva A, Pereira T, Sampaio-Maia B, Vasconcelos M. The effect of water and sodium hypochlorite disinfection on alginate impressions. Revista Portuguesa de Estomatologia, Medicina Dentária e Cirurgia Maxilofacial. 2013 Jan 1;54(1):8-12.

26. Al Mortadi N, Al-Khatib A, Alzoubi KH, Khabour OF. Disinfection of dental impressions: knowledge and practice among dental technicians. Clinical, cosmetic and investigational dentistry. 2019;11:103.

27. Woo J, Anderson R, Maguire B, Gerbert B. Compliance with infection control procedures among California orthodontists. Am J Orthod Dentofacial Orthop. 1992; 10: 268-75.

28. Vendrell RJ, Hayden CL, Taloumis LJ. Effect of steam versus dry-heat sterilization on the wear of orthodontic ligature-cutting pliers. Am J Orthod Dentofacial Orthop. 2002; 121;467-71.

29. Wichelhaus A, Bader F, Sander FG, Krieger D, Mertens T. Effective Disinfection of Orthodontic Pliers. J Orofac Orthop. 2006; 67:316-36.

30. Oshagh M, Hematiyan MR, Mohandes Y, Oshagh MR, Pishbin L. Autoclaving and clinical recycling: Effects on mechanical properties of orthodontic wires. Indian J Dent Res. 2012; 23: 638-42. 